\title{
The ICT and gamification: tools for improving motivation and learning at universities
}

\author{
Serrano, J. Javier ${ }^{a}$ and Fajardo, Félix ${ }^{b}$ \\ ${ }^{a}$ Geography Department, University of Valencia, Valencia-Spain. Beneficiari del programa \\ d'ajudes per a la formació de personal investiador de caracter predoctoral, en el marc del \\ Subprograma "Atracció de Talent” del Vicerectorat d'Investigació I Política Científica de la \\ Universitat de València. ; ${ }^{b}$ Geography Department, University of Valencia, Valencia-Spain. \\ Beneficiario de la ayuda para contratos predoctorales para la formación de profesorado \\ universitario, convocatoria 2014 (FPU14/05550), financiada por el Ministerio de \\ Educación, Cultura y Deporte.
}

\begin{abstract}
The teacher-student technology gap and the lack of attention in the design of attractive and motivating learning methodologies often result in student's demotivation and poor academic performance. To this end, from the research field, a series of methodologies and tools have been developed, such as gamification, as well as the introduction of ICT in lessons.

By implementingSocrative, a classroom app to engage students, we tried to measure the evolution of students' knowledge after the use of ICT and more interactive lessons. In addition, we tried to relate the level of motivation to students' seating plan in the classroom (in rows). We also tried to analyse students' preferences and their feedback of the new techniques and methodologies used during the classes.

The main result of the research is that the use of ICT and gamification in the classroom improved students' motivation and learning, especially those who were less motivated. The direct relation between the students' seats in the classroom and their motivation was verified. At the same time, the learning differences between all the students in the classroom were reduced, achieving a balance between the learning and the motivation of the students.
\end{abstract}

Keywords: Smartphone; incentive; learning; university students; Socrative. 


\section{Introduction}

In recent decades, Information and Communication Technologies (ICT) have experienced a rapid technical progress that has resulted in new forms of social relations and new channels of transmission of information. These changes modified the behaviour of all age-groups, but the main impact have been on the most recent generations ${ }^{1}$, where the use of ICT are as daily as any other basic activity of the day. These new generations have grown up in a digital and interconnected environment and they respond to stimuli and interests in different ways compared to previous generations. However, in most cases this "student body 2.0" receives training based on traditional teaching methodologies, such as strictly theoretical classes. In many cases, this is due to the fact that educational professionals have failed to understand the impact that ICT have introduced in the life of students (Fructuoso, 2015). Additionally, in the university environment many teachers assume that students are motivated, supposedly, because this level of education is voluntary and theoretically students enroll in those degrees which best fit their interests. However, it is a mistake to think that students are naturally motivated by the learning process (Lopez, 2004).

The teacher-student technology gap and the lack of attention in the design of attractive and motivating learning methodologies often derive in demotivation and low academic performance on the part of the student body. The motivated and resilient students do so in the face of any situation and/or teaching methodology, however the unmotivated students don't do it. Therefore, it is necessary to research new learning methodologies that manage to attract the interest of those unmotivated students since it is fully demonstrated that a motivated student will achieve a higher academic performance that, in general, will become a better performance of their professional activity (Rinaudo Et al., 2004).

Two great typologies of motivation can be distinguished: intrinsic and extrinsic motivation (Condry and Chambers, 1978; Pekrun, 1992; Anaya and Anaya, 2010). Intrinsic motivation is the one that is under the control of each person and has the ability to self-reinforce; while extrinsic motivation is the one that depends on external factors and affects the performance of tasks (Anaya and Anaya, 2010). There is an extensive literature on the factors that influence the motivation of student learning. Some authors state that the realization of classes with varied activities, less theoretical and more interactive, contributes to increase the motivation of students (Mosquera, 2003). Some of these activities are the viewing and commentary of documentaries, the realization of debates with assignment of roles and even the accomplishment of contests and quizzes based on the subject explained in previous classes, reassuring the knowledge of concepts alreadytaught.

\footnotetext{
1 These new generations born between 1994/95 until 2010 are known by the researchers by the name of "Z Generation", "Generation of the Millennium" or "Digital natives", which have a greater dependence on the virtual world and the technologies, getting to have a digital hyperactivity.
} 
It is important to understand that "new students" have incorporated the dynamics of games and digital environments (freedom of decision, speed of decision making, immediacy of response, personalisation of the environment and action) to their behavioural logic. The introduction of these game dynamics into teaching practice has proved to be a very effective method in the process of knowledge acquisition; this technique has been testedin different knowledge contexts and their educative effects have been proved (Labrador et al., 2016). This technique based on the incorporation of game methodologies to improve the motivation in the learning processes is called "gamification" (Sánchez, 2015).

The following is a case study, carried out with the students of the subject of Geography of Europe of the Degree of Geography and Environment of the University of València, where some innovative methodologies and teaching tools have been applied and little used in the universities in order to improve students' motivation and performance.

\section{Objectives and Hypothesis}

The main objective was to measure the evolution of the students' knowledge of the Geography of Europe subject of the Degree of Geography and Environment, after applying a theoretical-participative teaching methodology where the gamification and the use of ICT would have a significant weight. In addition, we also sought to know the opinions and preferences of students regarding the teaching methodology used.

The study starts from a series of initial hypotheses:

- The distribution of students in the classroom is related to their motivation, hence the students with a lower level of motivation are in the rear rows.

- The introduction of participation techniques and ICT will improve the performance of students, especially those who are less motivated.

- The students have a greater preference for participatory teaching methodologies with a greater use of ICT.

\section{Methodology}

The group of study/control group was made up of the students of the subject of Geography of Europe of the first course of the Degree of Geography and Environment of the Universitat de València. The proposed methodology was developed along the thematic unit IV of the subject, within the framework of the mentoring program of the Formación Integral del Profesorado Universitario (FIPU) taught by the Servei de Formació Permanet i Innovació Educativa (SFPIE) of the Universitat de València.

For the study, we analysed the results of the students who participated in all the activities carried out, obtaining a sample of 24 individuals. The results of the students who often did 
not attend the lessons and who, therefore, were not involved in all the proposed activities, were not taken into account. Throughout the research process the students kept the same seats (in rows) they chose the day of the initial test.

During the development of the classes the theoretical explanation was combined with activities that required the direct participation of students such as the viewing of audiovisual material and reading of documents, commentaries, debates, and group discussions as well as the realization of games and quizzes related to the subject explained in class. The lessons followed the structure below:

1. Sample Student Ranking and review of questions with worse results.

2. Theoretical-Practical classes (viewing of documentaries, readings, debates, quizzes by groups, etc).

3. Test on the subject taught during the session.

\subsection{Applications}

Initially, three programs were selected: Kahoot, Spiral and Socrative. The main feature that unite these programs is their free access on the internet, which was necessary for students to do it. In addition, all three programs are compatible with Android and IOS, so students could use them in class on their laptops, tablets or smartphones. Starting from these common characteristics, we analised and tested the different programs in order to identify strengths and weaknesses of each one. Finally we decided to select Socrative.

Socrative is an application that allows interaction between students and teachers in an instantaneous way through activities that provide and immediate vision of the students' understanding. Additionally, the playful approach of this app encourages participation and increases student motivation.

Socrative was the program selected for our analysis, since it was the one that most adapted to our needs and our students' for several reasons. On one hand, it allows to create questions for the students in several ways: Multiple choice, True/False and/or Short Answer). On the other hand, it allows to carry out questionnaires by combining all types of questions (the 3 typologies marked above) with no time limit, showing whether each answer is correct and allowing the answers from the students to be anonymous or not. In addition, it allows to perform "competitions" individually or by groups (the latter was very useful for the motivation of the students). Moreover, it was only necessary students' devicesin order to visualise the questions and answer to them. Finally, further analysis was facilitated by the fact that the results from each activity can be downloaded and reports can be sent which summarise students' answers in Excel format. 


\subsection{The questionnaire}

The questionnaireswere done digitally andhad a playful approach. The use of ICT made possible to convert traditional tests into quizzes by creating a very different atmosphere from usual exams. In addition, ICT madepossible to compile data and compare reports, whose analysis allowed to establish the rhythm, the progress and the difficulties experienced by students throughout the school stage. This information is very useful for both students and teachers (Vivancos, 2013 ).

Each student used an alias composed of the first letter of his forename and their last name and a number (corresponding to the row where he/she used to sit in class). Moreover, at the beginning of each lesson a list was presented with the alias used by the students and the number of correct answers in the previous lesson, in order to motivate them and lead them to pay more attention in class and answer more right questions in the following questionnaire.

\subsection{Measuring the evolution of learning}

An initial diagnosis, a follow-up evaluation and a final evaluation were carried out to measure students' evolution. The realization of an initial diagnosis about the students' knowledge allowed the teacher to design and plan the lessons with a greater emphasis on those aspects in which the students presented greater difficulties. In addition, it allowed to detect the lack of knowledge about concepts that students should know (explained in previous courses or in high school) and, therefore, it allowed to build the knowledge on a solid base based on the understanding of basic aspects that became increasingly complex. In order to conduct the initial diagnosis, a questionnaire was designed with basic and general questions related to Topic 4 of the subject of Geography of Europe entitled "Recent Economic Processes in Europe". This questionnaire was given out to the students in the class prior to the beginning of the subject in question.

The follow-up evaluation allowed the students to verify their own progress and the teacher was able to check the degree of knowledge acquisition by the students in a constant way and to pay more attention to those aspects that presented greater difficulty for students. Moreover, periodic tests, even if they had a superficial approach, could contribute to increase students' motivation and increase their performance (Rinaudo et al., 1997). The follow-up evaluation was carried out at the end of each class and consisted of a short questionnaire with questions related to the aspects discussed during the session. Those issues that obtained a higher percentage of error wereexplained again at the beginning of the next session.

Finally, at the end of the thematic unit 4, a final evaluation was conducted with the issues addressed throughout the development of the thematic unit. In addition, a test was also 
carried out for students to express their opinions about the implemented activities during the thematic unit 4 in order to know their preferences and which activities were most beneficial to them in the learning process.

\section{Results}

The different tests allowed to measure the evolution of students' knowledge according to the row that they used to occupy. It is worth mentioning that the classroom never had full capacity and that the students did not complete all the rows. For this reason, the results are grouped in front rows (rows 1 and 2), intermediate rows (rows 3 and 4) and rear rows (rows 5 and 6).

A first analysis of the results showed that the proposed methodology was able to increase students' performance in relation to their starting situation. The results demonstrated that students' performance is inversely proportional to the order of rows they occupy during classes. As it can be seen in Table 1, the worst results obtained in the initial test correspond to the rear rows, while the highest scores are obtained in the front rows. These results confirm one of the first hypotheses, since generally the most motivated students sit in the front rows, while the rear rows are occupied by students with a minor interest towards the subject or to the methodology of the lessons.

Table 1. Average results by groups of rows (score over 100) and variation between the initial and final questionnaire

\begin{tabular}{|c|c|c|c|c|c|}
\hline Rows & $\begin{array}{c}\text { Initial } \\
\text { Test }\end{array}$ & $\begin{array}{c}\text { Final } \\
\text { Test }\end{array}$ & $\begin{array}{c}\text { Variation } \\
\text { between } \\
\text { both test }\end{array}$ & $\begin{array}{c}\text { Variation between } \\
\text { front rows and } \\
\text { others (Initial test) }\end{array}$ & $\begin{array}{c}\text { Variation between } \\
\text { front rows and } \\
\text { others (Final test) }\end{array}$ \\
\hline Front & 75,86 & 83,86 & 8 & - & - \\
\hline Intermediate & 72,5 & 81,78 & 9,28 & $7 \%$ & $2 \%$ \\
\hline Rear & 67,13 & 80,25 & 13,13 & $12 \%$ & $4 \%$ \\
\hline Total & $\mathbf{7 1 , 6 5}$ & $\mathbf{8 1 , 8 8}$ & $\mathbf{1 0 , 2 2}$ & $\mathbf{1 9 \%}$ & $\mathbf{6 \%}$ \\
\hline
\end{tabular}

Source: own elaboration.

The analysis of the results also allowed us to verify that after the application of the proposed methodology the rows that experienced a greater progress with respect to the initial test were the rear rows thus confirming another of the initial premises. The students in the rear rows obtained the worst results both in the initial test and in the final test, but after using the proposed methodology they were the students who made a greater progress compared to the initial situation, obtaining results which were very similar to those of the students in the front rows (Table 1).

Another of the objectives of the study was to know whether the teaching techniques or the practices used throughout the thematic unit contributed to the motivation and learning of 
the students. Based on the information gathered in the student opinion survey, $86 \%$ of students preferred theoretical-participative classes versus purely theoretical classes. $87 \%$ of the students valued between positive and very positive the use of new technologies in the classroom and $68 \%$ of students affirmed that they felt more motivated during the development of thematic unit 4 (Figure 1). In addition, $87 \%$ valued positively the use of ICT in the classroom.

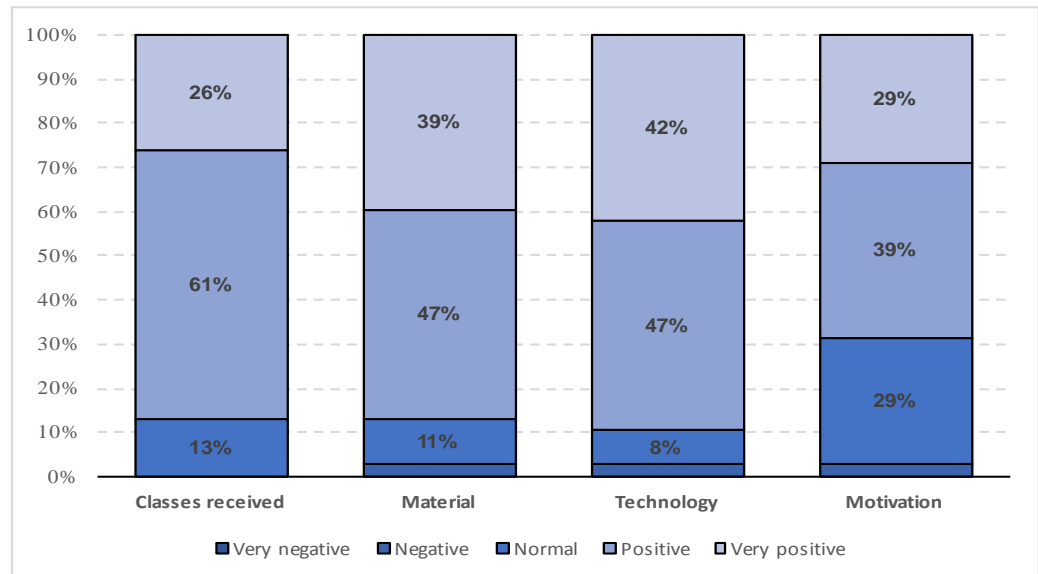

Figure 1. Student evaluation regarding the methodology and material used in class. Source: own elaboration.

As shown in figure 2 according to the students, the materials which they acquired greater knowledge with are the individual tests at the end of each session (32\% of the students), followed by the master classes $(27 \%)$ and the viewing of documentaries and teamwork $(16 \%)$; they learnt less with the debates $(-17 \%)$ and the readings and teamwork $(-17 \%)$. 


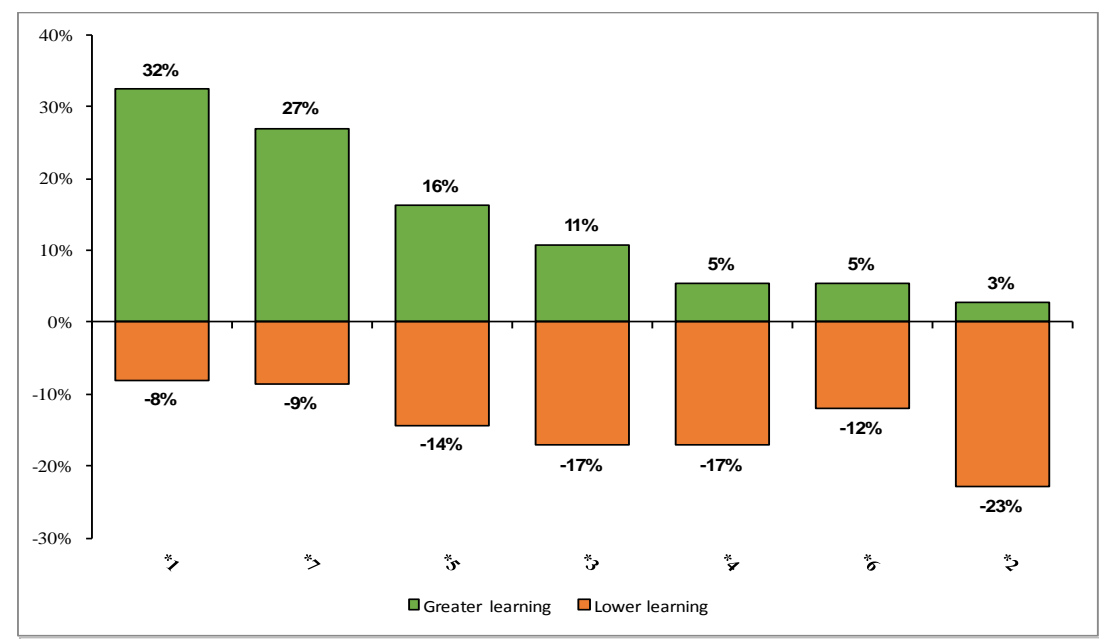

*1 (Indiv. mobile test); *2 (Colect. mobile test); *3 (Debate); *4 ( Reading and teamwork); *5 (Viewing documentaries and teamwork.); *6 (Graphics and teamwork.); *7 (Master class)

Figure 2. Assessment of the students of the techniques used in the classroom according to therir learning: own elaboration

\section{Conclusions}

The theoretical-participative classes, the introduction of gamification, and the use of ICT in the classroom are proved to be positive for both teachers and students who have participated in the present study. On one hand, teachers were able to obtain immediate information about the level of knowledge and the difficulties of their students, making possible to reorient the theoretical sessions towards those concepts that presented major problems. On the other hand, the use of ICT and the gamification approach of some of the exercises improved the motivation of the students towards the subject, especially in those students who started with a lower level of knowledge. Finally, given that the present study is a pilot study, it is considered interesting to carry out a more exhaustive investigation (different courses, different grades, different classes), in order to verify the transversality of the statements made here. 


\section{References}

Anaya, A. y Anaya, C. (2010) ¿Motivar para aprobar o para aprender? Estrategias de motivación del aprendizaje para los estudiantes. Tecnologías de Ciencia de la Educación (IMIQ), 25 (1), 5-14.

Condry, J., Chambers, J. 1978. Intrinsic motivation and the process of learning. En The Hidden Costs of Reward. Lepper, M.R., Greene, D. Eds. Lawrence Erlbaum Associates. Pp. 61-84. Hillsdale, NJ. EEUU.

Fructuoso, I. N. (2015). How Millennials are changing the way we learn: the state of the art or ICT integration in education. RIED, Revista Iberoamericana de Educación a Distancia, 18(1), 45-65.

Labrador, E., \& Villegas, E. (2016). Unir Gamificación y Experiencia de Usuario para mejorar la experiencia docente. Revista Iberoamericana de Educación a Distancia, 19(2), 125-142.

López L. (2004). La motivación en el aula. Pulso, 24, 95-107.

Mosquera I. (2003). Motivación y rendimiento en la Universidad: el papel de los docentes. Revista Galego-Portuguesa de Psicoloxía e Educación, 8 (7), 333-340.

Pekrun, R. 1992. The impact of emotions on learning and achievement: Towards a theory of cognitive/motivational mediators. Applied Psychology: An International Review. 41(4):359-376.

Rinaudo M. C., De la Barrera M.L. \& Dilvio D. (1997). Motivación para el aprendizaje en alumnos universitarios. Revista Electrónica de Motivación y Emoción, 11 (22).

Sánchez, F.J. (2015). Gamificación. Eduaction in Knowledge Society, 16(2), 13-15.

Vivancos, J. (2013). El Futuro de la Educación y las TIC. Padres y Maestros, 351, 22-25. 